\title{
Effectiveness of an Educational Program among Mothers on Household Poisoning in Children in the Rural Community
}

\author{
Mehvish Yaqoob $^{1^{*}} \quad$ Muhammad Hussain $^{2} \quad$ Iram Majeed $^{3} \quad$ Muhammad Afzal $^{4}$ \\ Kausar Parveen ${ }^{4}$ Syed Amir Gilani ${ }^{5}$
}

1.BS Nursing, Lahore School of Nursing, The University of Lahore, PO box 54000, Lahore, Pakistan. 2.Assistant Professor, Lahore School of Nursing, the University of Lahore, PO box 54000, Lahore, Pakistan. 3.Nursing Instructor, Lahore School of Nursing, the University of Lahore, PO box 54000, Lahore, Pakistan 4.Associate Professor, Lahore School of Nursing, the University of Lahore, PO box 54000, Lahore, Pakistan 5.Professor, FAHS the University of Lahore, PO box 54000, Lahore, Pakistan.

\begin{abstract}
Introduction: Household poisoning is a worldwide problem. It is s a major cause of morbidity and mortality in children which includes cleaning products, kerosene, pesticides, cosmetics and medicines. Methods: A quasiexperimental, quantitative, before and after study design was conducted among the mothers total $(n=60)$ in the community of Ali Raza Abad Raiwind Road Lahore, Pakistan from September 2018 to December 2018. The educational interventions involve four meetings about household poisoning in which the researcher educate the mothers about household poisoning in children. Results: A total of 60 mothers participated in the study. The total mean of mothers before the educational intervention is 13.10 (Standard deviation 2.673) and after the educational intervention is 26.18 (Standard deviation 2.175). The mean difference between the two means is 13.083. There is a statistically significant difference before and after the educational intervention. The educational intervention is highly effective because the significant value is 0.00 . Conclusions:: The result of the study shows that educational intervention in mothers can effective to improve knowledge related to household poisoning in children.
\end{abstract}

Keywords- Household poisoning, Educational Program.

DOI: $10.7176 / \mathrm{JHMN} / 69-07$

Publication date: December $31^{\text {st }} 2019$

\section{INTRODUCTION}

Household Poisoning happens when hazardous substances are ingested or inhaled accidentally by children's. In children, $90 \%$ of the poisoning exposures occur in the home (Gielen et al., 2015). Child poisoning is a worldwide problem. It is $\mathrm{s}$ a major cause of morbidity and mortality in children which includes cleaning products, and medicines (Ahmadabadi et al., 2016).In young children, poisoning is a significant public health issue. Study shows that children of 1-3 years have the highest levels of poisoning risk (Schmertmann et al., 2013). Child poisoning commonly involves household products. Household products include personal care products, household cleaners, pesticides, and medications (Mowry et al., 2015). Children try to search Household products from cupboards and shelf and consume them while playing outside. Mostly, insecticides and pesticides are present in garden sheds which become the cause of poisoning in them (Shirdelpour et al., 2017). In-home household products are placed in plastic bottles of soft drinks. This leads to curiosity in children to attract towards them. Mothers should be cautious to place products out of children approach. Moreover, educational measures are considered necessary among mothers on household poisoning in children to keep children safe and out of reach of these products (Nistor et al., 2018). Ingestion was a most common route of poisonous substances comprising of $75.5 \%$ poisoning in children. Medication poisoning is the most occurring poisoning exposure among children includes $27.6 \%$ of Paracetamol. Children easily approach to medicine as it is easily accessible and used by a family in daily routine. In children, 1-7 year age is the most common vulnerable age of toxicity $(74.8 \%)$. Medication poisoning among children causes hyperthermia. Also, the most presenting symptoms in the current research were GIT upset, vomiting (24.9\%). Effective education programs for parents and careers regarding poisoning hazards are needed to increase awareness and reduce the incidence of poisoning among children (Ragab \& Al-Mazroua, 2015). The high risk of chemical poisoning observed in children requires health education on chemical safety among mothers to prevent access to toxic agents mainly in homes (Z'gambo et al., 2016). Awareness and education about the toxicity of commonly used pesticides and drugs may help in reducing the burden of poisoning. Patterns and causal agents of poisoning vary from region to region (Gupta et al., 2016).

Pediatric unintentional self-poisoning is increasing day by day due to easy accessibility of household medicines, chemicals and pesticides. It has severe health hazards with high morbidity rate (Dayasiri et al., 2017). Children poisoning include substances that are cosmetics and personal care products (14\%), analgesics (10\%) and household cleaning substances also $10 \%$ (Glenn, 2015).

Household Kerosene is a common cause of Poisoning. It is a significant and preventable cause of morbidity and mortality. Kerosene oil poisoning is one of the common presentations to emergency departments among children in rural territories of developing countries. A huge amount of kerosene is uncommon because of its foul 
smell and taste (Anwar et al., 2014). Child-resistant containers and safety education among mothers were effective in reducing poisoning ingestion in children (Bhatta, 2017).

\section{II.MATERIAL \& METHODS}

Setting

The setting of the study was a community of Ali Raza Abad located on Raiwind Road Lahore Punjab Pakistan.

\section{Research design}

The quasi-experimental study design was used in this study by using a pre and post-test phase.

\section{Population}

The target population of the study was mothers of children of age group 1-7 year of Ali Raza Abad community, Raiwind Road Lahore.

\section{Sampling}

Convenient sampling techniques were used in this study for data.

\section{Research instrument}

A well-structured and adopted questionnaire from the study of ( Raj, A., 2013)was used to collect the data from the participants.

\section{Data gathering procedure}

A formal written letter of permission to conduct the research. And the questionnaire was distributed to the mothers.

\section{Analyze data}

Data analysis was done by comparing pretest and a post-test score of the questionnaire with the use of paired t-test in SPSS version 21 statistical software for data analysis, in pre and post-test results. A 95\% confidence level is used for the study and a $P \leq 0.05$ was considered statistically significant.

\section{Scoring and Grading of knowledge Responses}

There were twelve stem questions on knowledge of food safety and hygiene with fifty responses. Only thirty-three of those responses were correct. One mark awarded for every correct response and no mark for wrong or I don't know the response and a total of thirty-three most possible scores were used for knowledge of food safety and hygiene. A score of 0-11 marks out of thirty-three marks was graded be poor knowledge, a score of 12-22 marks out of thirty-three marks was graded as honest knowledge and a score of 23-33 marks out of thirty-three marks was graded pretty much as good knowledge.

\section{Ethical consideration}

All the rules and regulations administered by the ethical committee of Lahore Schoool of Nursing, The University of Lahore all the informed consent taken from all the participants. All the data kept confidential.

\section{Study timeline}

Duration of the study was 4 month (September 2018 to December 2018)

\section{III.RESULT}

This section presents the outcomes of the study. PROFILE OF THE RESPONDENTS

Respondents were taken from the rural community of Ali Razaabad.

Research Question 1 - To evaluate the effectiveness of an educational program among mothers on household poisoning in children in the rural community. 


\begin{tabular}{|ll|rr|r|r|rr|}
\hline \multicolumn{2}{|l|}{ Paired Samples Statistics } \\
\hline & & Mean & N & & Std. Deviation & Std. Error Mean \\
\hline \multirow{2}{*}{ Pair 1 } & Pre & 13.10 & 60 & 2.673 & .345 \\
& Post & 26.18 & & 60 & 2.175 & .281 \\
\hline
\end{tabular}

\begin{tabular}{|c|c|c|c|c|}
\hline \multicolumn{5}{|c|}{ Paired Samples Correlations } \\
\hline & & $\mathrm{N}$ & Correlation & Sig. \\
\hline Pair 1 & Pre \& Post & 60 & .125 & .000 \\
\hline
\end{tabular}

\begin{tabular}{|c|c|c|c|c|c|}
\hline \multicolumn{6}{|l|}{ Paired Samples Test } \\
\hline & \multicolumn{5}{|c|}{ Paired Differences } \\
\hline & \multirow[t]{2}{*}{ Mean } & \multirow[t]{2}{*}{ Std. Deviation } & \multirow[t]{2}{*}{ Std. Error Mean } & $\begin{array}{l}95 \% \text { Confidence } \\
\text { Difference }\end{array}$ & Interval of the \\
\hline & & & & Lower & Upper \\
\hline Pair 1 Pre - Post & -13.083 & 3.227 & .417 & -13.917 & -12.250 \\
\hline
\end{tabular}

Paired Samples Test

\begin{tabular}{|l|r|r|r|}
\hline & T & df & \multicolumn{1}{|c|}{ Sig. (2-tailed) } \\
\hline Pair 1 Pre - Post & -31.400 & 59 & .000 \\
\hline
\end{tabular}

The total mean of mothers before the educational intervention is 13.10 (Standard deviation 2.673) and after the educational intervention is 26.18 (Standard deviation 2.175). The mean difference between the two means is 13.083. There is a statistically significant difference before and after the educational intervention. The educational intervention is highly effective because the significant value is 0.00 and that is why the null hypothesis will be rejected and alternative hypotheses will be accepted.

\section{IV.DISCUSSION}

The present study shows that health education has a great impact among mothers on household poisoning in children as is evident through the post data result in which the p-value indicated the positive effect which is $(0.00)$. Mean before the educational intervention was 13.10 which is significantly increased after the effective educational intervention to 26.18 that is why the null hypothesis is rejected in favour of the alternative hypothesis. The results of the similar study show that mothers knowledge were correct after the program regarding definition, risk factors and prevention of household poisoning respectively compared to $66 \%, 56 \%, 64 \%$ before the program that reflects statistical significant difference $(\mathrm{X} 2=18.9$ with $\mathrm{p}<.05)$ pre and post the program. Regarding the total score of correct studied mothers' knowledge was $94 \%$ after program implementation compared to $38 \%$ before the program with statistically significant difference $((\mathrm{X} 2=29.8, \mathrm{P}=<.05)$ (Mona Ali Kunswa., 2018).

The study shows the majority of the educational status of mothers is primary education (30\%), $(26 \%)$ secondary education, only (4\%) are graduate. In another study the educational level of the studied mother was secondary education, this result was in contradiction with this study (Dayasiri et al., 2017).

This study shows occupation of mothers that majority (43\%) are housewife's, $(5 \%)$ of the subjects have a private occupation, 7\% have government occupation, (3\%) self-employed. Only (2\%) have a semi-government occupation. In another study $74.5 \%$ of the mothers were housewives and $19.3 \%$ were civil servants. (SIvrI \& OzpuLat, 2015).

This study shows that educational interventions were effective. The knowledge among mothers on household poisoning of children was increased. A similar study conducted shows through a survey that $48 \%$ of poisoning in children occurred at home. Educational interventions are performed in 22 out of 35 houses. Whereas in 7 houses no education was given on child poisoning to parents. (SIvrI \& OzpuLat, 2015).

This study shows that through education and preventive measures children were safe from poisonous substances at home. Through active preventive measures such as by using child-resistant packaging for medicines and household products and giving education to the mothers reduces exposures to poisonous products as children do not have access to them(Nistor et al., 2018).

This study evaluates that safe storage and health education among mothers are effective interventions for reducing unintentional poisoning risk in children of the community. The similar study evaluates that safe storage 
and health education among mothers are effective interventions for reducing unintentional poisoning risk in children of the community (Mansori et al., 2016).

\section{Limitations}

A more comprehensive study needs to be examined with more generalizability by increasing sample size because this study has a small sample size and conducted in only one community.

\section{Conclusion}

It is concluded that educational intervention in mothers is much effective to improve knowledge and appropriate behaviour related to household poisoning in children. Educational intervention related to household poisoning in children has the potential to make a great impact on the health of children. The motivation of mothers is needed for their role to prevent household poisoning in children. In this study, the educational program accomplishes a significant effect on mothers

\section{Acknowledgement}

This research work was not possible without the help and encouragement of many individuals to whom I am very grateful. First and foremost, I would like to thank Mr. Muhammad Afzal (The Principal of the Lahore School of Nursing) who allowed me for this study. Sir Muhammad Hussain and Ms Irum Majeed, for being my preceptors and for being the greatest inspiration for my work when I had no idea to perform research work, and who has been supportive and encouraging me throughout the whole process and freely offered their precious time to help me. Without their willingness to guide me in this study, this research work would not have come to completion. I am also grateful to my teacher Sir Muhammad Azhar, my friends and all those people who I contacted during this process. I also thank the management of the University of Lahore.

Last but not least, I would like to thank my parents who provided endless moral, financial and motivational support for me during this research work.

\section{References}

1. Ahmadabadi, F., Davoodi, A., Ahmadabadi, F., \& Rezazadeh, H. (2016). Unintentional Poisoning in Children Admitted to Tabriz Pediatric Hospital. Pharmaceutical Sciences, 22(2), 132.

2. Anwar, S., Rahman, A., Houqe, S. A., Moshed, A., Yasmin, L., Saleh, A., \& Mohsin, M. (2014). Clinical profile of kerosene poisoning in a tertiary level hospital in Bangladesh. Bangladesh Journal of Child Health, 38(1), 11-14.

3. Banerjee, S., Paul, B., Bandyopadhyay, K., \& Dasgupta, A. (2016). Domestic unintentional injury of 1 to 5year-old children in a rural area of West Bengal, India: a community-based study. Tanzania Journal of Health Research, 18(3).

4. Bell, J. C., Bentley, J. P., Downie, C., Cairns, R., Buckley, N. A., Katelaris, A., . . . Nassar, N. (2018). Accidental pharmacological poisonings in young children: a population-based study in three settings. Clinical toxicology, 1-8.

5. Bhatta, S. (2017). Community-based home injury risk assessment in rural Nepal. The University of the West of England.

6. Dayasiri, M., Jayamanne, S. F., \& Jayasinghe, C. Y. (2017). Risk Factors for Acute Unintentional Poisoning among Children Aged 1-5 Years in the Rural Community of Sri Lanka. International Journal of paediatrics, 2017.

7. Gielen, A. C., McDonald, E. M., \& Shields, W. (2015). Unintentional home injuries across the life span: problems and solutions. Annual review of public health, 36, 231-253.

8. Glenn, L. (2015). Pick Your Poison: What's New in Poison Control for the Preschooler. Journal of pediatric nursing, 30(2), 395-401.

9. Gupta, P., Kumar, A., Singh, S. P., Prakash, M., Gupta, M., \& Kumar, P. (2016). The pattern of Cases of Acute Poisoning in a Rural Tertiary Care Center in Northern India. National Journal of Community Medicine, 7(4), 307-310.

10. Khan, N. U., Khan, U. R., Feroze, A., Khan, S. A., Ali, N., Ejaz, K., . . Fayyaz, J. (2016). Trends of acute poisoning: 22 years of experience from a tertiary care hospital in Karachi, Pakistan. Journal of the Pakistan Medical Association, 66(10), 1237.

11. Khan, U. R., Chandran, A., Zia, N., Huang, C.-M., De Ramirez, S. S., Feroze, A., . . Razzak, J. A. (2013). Home injury risks to young children in Karachi, Pakistan: a pilot study. Archives of disease in childhood, arch dis child-2013-303907.

12. Kumari, P., \& Sharma, S. (2018). Knowledge of Mothers about the Risk of Domestic Accident among Toddlers: Effectiveness of Strategy for Teaching about Home Safety. Research \& Reviews: Journal of Medicine, 7(3), 1-7. 
13. Mansori, K., Soori, H., Farnaghi, F., \& Khodakarim, S. (2016). A case-control study on risk factors for unintentional childhood poisoning in Tehran. Medical journal of the Islamic Republic of Iran, 30, 355.

14. Mowry, J. B., Spyker, D. A., Brooks, D. E., McMillan, N., \& Schauben, J. L. (2015). 2014 annual report of the American association of poison control centres' national poison data system (NPDS): 32 nd annual report. Clinical toxicology, 53(10), 962-1147.

15. Nistor, N., Frasinariu, O. E., Rugină, A., Ciomaga, I. M., Jităreanu, C., \& Ştreangă, V. (2018). Epidemiological study on accidental poisonings in children from northeast Romania. Medicine, 97(29).

16. Parmeswaran, G., Kalaivani, M., Gupta, S., Goswami, A., \& Nongkynrih, B. (2016). Assessment of home hazards for childhood injuries in an urban population in New Delhi. Child: care, health and development, 42(4), 473-477.

17. Raj, A. (2013). A study to evaluate the effectiveness of structured teaching program regarding household poisoning in children among mothers in a selected rural area of Bangalore.

18. Ragab, A., \& Al-Mazroua, M. (2015). The pattern of pediatric toxicity in Saudi Arabia-Eastern province (incidence, demographics and predisposing factors). Pediat Therapeut, 5(220), 2161-0665.1000220.

19. Schmertmann, M., Williamson, A., Black, D., \& Wilson, L. (2013). Risk factors for unintentional poisoning in children aged 1-3 years in NSW Australia: a case-control study. BMC paediatrics, 13(1), 88.

20. Shirdelpour, K., Shafipour, S. Z., Mirzaei, M., Kazem Nejad Leili, E., \& Nath, A. (2017). Poisoning and its Related Factors in Children under 6 Years Old in Rasht. Journal of Holistic Nursing And Midwifery, 27(2), 85-92.

21. Shriyan, P., Prabhu, V., Aithal, K. S., Yadav, U. N., \& Orgochukwu, M. J. (2014). Profile of unintentional injury among under-five children in coastal Karnataka, India: a cross-sectional study. Age (years), 3(18), 40.49.

22. SIvrI, B. B., \& OzpuLat, F. (2015). Mothers' knowledge levels related to poisoning. Turkish Journal of Emergency Medicine, 15(1), 13-22.

23. W.H.O. (2016). World health statistics 2016: monitoring health for the SDGs sustainable development goals: World Health Organization.

24. W.H.O. (2017). World health statistics 2017: monitoring health for the SDGs, sustainable development goals.

25. Z'gambo, J., Siulapwa, Y., \& Michelo, C. (2016). The pattern of acute poisoning at two urban referral hospitals in Lusaka, Zambia. BMC emergency medicine, 16(1), 2. 